\title{
PLANEJAMENTO URBANO E PARTICIPAÇÃO POPULAR: HÁ UMA FÓRMULA PARA A CIDADE QUE SONHAMOS?
}

\author{
José dos Reis Santos Filho'
}

Simone Crisina de Oliveira ${ }^{2}$

\section{Stefania Wludarski ${ }^{3}$}

Resumo: O texto é uma nova aproximação dos autores a um tema cujo núcleo é a questão da gestão meio ambiental com enfoque na sustentabilidade. A preocupação aqui apresentada refere-se à questão da participação popular e traz alguns exemplos quanto ao protagonismo do Estado em relação ao tópico. Mostra que a legislação brasileira é atualíssima em relação ao assunto e que ela estaria em condições de lidar com as "ruínas", com as "regressões" resultantes de uma visão de progresso que marca o processo civilizatório ocidental. Sugere a necessidade de "alargar os espaços de participação da grande massa popular nas decisões". Reconhece, nesse quadro, a importância da mudança da realidade através da mudança do próprio sujeito da transformação. E, justo por reconhecer isso, aponta a fundamentalidade da educação ambiental. Pede ajuda a exemplos tirados de Araraquara, cidade do interior paulista para mostrar os limites e as possibilidades de

\footnotetext{
1 Unesp/FCL/CAr. Departamento de Sociologia. Núcleo de Estudos e Pesquisas sobre Sustentabilidade e Desenvolvimento Urbano Ambiental.reis.meioambiente@gmail.com

${ }^{2}$ Engenheira Agrônoma (UFV). Mestre em Sociologia (Unesp/FCL/CAr). Doutoranda em Engenharia Urbana (UFSCar). simonecoliv@gmail.com

${ }_{3}$ Administradora Pública (Unesp/FCL/CAr). Especialista em Gerência de Cidades. stefaniawlu@gmail.com
} 
avançar em um paradigma de participação popular na construção de uma sociedade sustentável.

Palavras-chave: Planejamento urbano. Participação popular. Meio ambiente.

\section{INTRODUÇÃO}

A discussão acerca do planejamento urbano ambiental e da participação popular não é nova. Entre nós, como veremos adiante, no campo jurídico, foi introduzida de forma contundente a partir da Constituição Federal de 1988 e especialmente do Estatuto da Cidade. Da década de 90 em diante, tornou-se tema necessário de políticas de desenvolvimento municipal e, certamente, de debates entre especialistas.

Entre as controvérsias que alimentou, há um eixo que chama atenção pela importância que adquiriu nos estudos referentes aos processos de formação das cidades e os impactos que esses processos acarretaram e acarretam no ambiente natural. Antecipada pela legislação dos anos 90 nos referimos basicamente à relação entre o presente e o futuro dos núcleos urbanos e à participação dos seres que neles habitam nas definições sobre o significado dos espaços em que vivem e em que gostariam de viver.

Dinâmicos e objetos de múltiplos vetores de forças que expressam interesses e/ou clamam por direitos, os caminhos e procedimentos que fazem parte do jogo que determina o futuro das cidades tornaram-se campos de luta em que se encontram os mais diversos agentes. Nesse quadro, um ponto fundamental a ser enfrentado é o da permeabilidade da arena política e os canais de que dispõe para criar relações dialógicas com a sociedade e, por conseqüência, garantir as exigências da lei em torno do envolvimento da população. 
De fato, a própria idéia de participação encontra-se no centro das inquietações. Algo que as ruas e a bibliografia já denunciaram reiteradas vezes. ${ }^{4}$ Assim, se é verdade que a existência de anéis burocráticos articula e facilita as relações entre as elites dirigentes do Estado e aquelas de empresas, de representantes dos grandes interesses privados, ${ }^{5}$ isso já não ocorre com o grosso da população e, mesmo, com parte significativa de seus segmentos organizados. No núcleo da questão, portanto, as garantias e, mesmo, as possibilidades de uma participação efetiva, informada, enfim, cidadã, dos habitantes de uma cidade nos destinos do espaço em que vivem.

Há, no entanto, outra faceta do problema, parte de sua própria natureza, que reivindica tratamento específico. Qual seja, o da compreensão, por parte da população, sobre a fundamentalidade de seu envolvimento nos processos decisórios. É algo que obriga e abriga uma bela quantidade de elementos. Parte significativa deles já foi enfrentada pela literatura. ${ }^{6}$ Objeto de nossa atenção, nos limitaremos aqui a uma de suas dimensões, aquela que sinaliza a mudança da realidade através da mudança do próprio sujeito da transformação. Em outras palavras: supomos que, na defesa do meio ambiente, quadro mais amplo de nossa reflexão, sua preservação e desenvolvimento dependem de forma imprescindível de uma atitude pró-ativa por parte dos sujeitos. Sujeitos, devemos ser realistas quanto a isso, cujas trajetórias podem ter sido de desconhecimento, de indiferença ou, mesmo, agressão/cumplicidade em relação à questão ambiental. Tendo Marx das Teses contra Feuerbach em mente, mas modificando o horizonte de sua análise, sugerimos que lidar com a questão da participação da população na mudança das contingências que tornaram a realidade meio ambiental sinônimo de degradação é

\footnotetext{
${ }^{4}$ As manifestações de junho são evidências recentes. Na literatura, as palavras de OLIVEIRA sobre o período presidencial de Lula são paradigmáticas e de atualidade: o que permanece como tarefa histórica, no sentido clássico que a sociologia política aplicou ao termo, são avanços na socialização da política em termos gerais e, especificamente, o alargamento dos espaços de participação nas decisões da grande massa popular, intensa redistribuição da renda num país obscenamente desigual e, por fim, uma reforma política e da política que desse fim à longa persistência do patrimonialismo. Os grifos são nossos. OLIVEIRA, 2007.

${ }^{5}$ Sobre o tema, ver HABERMAS, . Para seu desenvolvimento doméstico, consultar CARDOSO, .

${ }^{6}$ Ver, na qualidade de bom exemplo dessa literatura, CHAUÍ, 1986. Em especial, o capítulo que dá nome à obra.
} 
uma prática envolta em um processo educacional. ${ }^{7} \mathrm{Ou}$, de outra forma: participação é, aqui, aprendizagem tornada prática transformadora.

O objetivo específico deste artigo é mostrar, portanto, por meio de uma reflexão motivada por exemplos ocorridos em Araraquara, município da região central de São Paulo, como a educação ambiental pode ser instrumento de transformações de natureza subjetiva e objetiva. No trajeto, tentaremos recuperar faces de uma história que nos trouxe à situação em que nos encontramos e os limites das políticas públicas voltadas para a participação popular.

\section{A PRÉ-HISTÓRIA}

Olhada em perspectiva acrítica, a história nos fez ver um tempo que, do passado ao presente, seria definido como de desenvolvimento. Essa história não fez questão de lembrar uma coleção de acontecimentos que só poderiam ser considerados como catástrofes, "ruínas" herdadas por cada nova geração. Ao omitir esses eventos, viu progresso no desenrolar dos eventos e, em nome dele, a humanidade foi impelida "incessantemente em direção ao futuro, enquanto a montanha de ruínas cresce". ${ }^{8}$ Resgatar, na esteira da nona Tese sobre a Filosofia da História, de Benjamin, a ambigüidade de uma visão do presente que esquece os problemas deixados pelo passado, problemas que, diga-se de passagem, comprometem o futuro, ${ }^{9}$ é mais que um dever de ofício. É um compromisso ético que impõe a necessidade de observarmos uma trajetória que é de conquistas, mas, não esqueçamos, conquistas que deixaram cicatrizes.

De fato, ao longo de toda sua história o homem foi obrigado a uma série de "liberações". Citando Leroy-Gouhan, Bourguignon lembra que o processo de hominização implicou na separação de seu corpo em relação ao elemento líquido, à adaptação frente às imposições térmicas do meio, à localização da cabeça em

\footnotetext{
${ }^{7}$ Referimos-nos, em particular, à Tese II. Ver MARX, 1976, p.1.

${ }^{8}$ BENJAMIN, 2013.

${ }^{9} \mathrm{Em}$ 1964, a noção em torno da grandeza dos problemas planetários era apresentado na forma de um alerta: "estimo que a humanidade após ter tomado consciência clara dos perigos que a ameaçam, vai entrar numa nova era de sua história". (SALK, 1973, apud Bourguignon, 1990. p.155).
} 
relação ao solo, às possibilidades das mãos na locomoção e, mesmo, da posição do cérebro quanto à máscara facial. ${ }^{10}$ Lembra ainda que, ao longo de milhares de anos, as condições foram criadas para o aprimoramento e a criação de instrumentos, o conhecimento da produção agrícola, a segregação de animais que se tornam domésticos e de tecnologias que permitem, por exemplo, a armazenagem de alimentos. E, com tudo isso, no que nos interessa mais diretamente, a passagem do nomadismo à sedentariedade. É a partir daí que podemos considerar a relação entre o processo de hominização e o processo civilizatório. As aldeias brotam da terra, as cidades nascem e os Estados surgem. ${ }^{11}$ Algo cuja lógica orientadora esteve assentada em um "desenvolvimento acumulativo da tecnologia produtiva e militar" que impôs "mudanças qualitativas de caráter radical", que, por sua vez, deu lugar a "etapas ou fases da evolução sociocultural" que determinaram as feições diferenciadas "nos modos de organização da sociedade e de configuração da cultura". (RIBEIRO, 2000, p. 11).

É esse o quadro que permite chamar de processo civilizatório às seqüências evolutivas genéricas, em que vemos difundirem-se os efeitos de um surto de inovações tecnológicas social e culturalmente incorporadas à vida das pessoas. ${ }^{12}$ É verdade que, levada às últimas conseqüências, a definição pode induzir à compreensão de uma trajetória civilizatória que não seria outra coisa senão avanço indefinido. ${ }^{13}$ De certa forma, essa é uma noção incorporada como dado natural, como pré-conceito e registro cognitivo desde há muito tempo. Nas palavras de Bury, esse é um entendimento precedido por reflexões que anunciaram ser constatável

uma evolução humana gradual desde um estágio primitivo e selvagem até um certo nível de civilização, mercê de uma série de

\footnotetext{
${ }_{11}^{10}$ BOURGUIGNON, op. cit. p. 157.

${ }^{11}$ Idem, p. 161.

${ }^{12}$ A matriz dessa definição pode ser encontrada em Ribeiro, 2000, p. 28.

13 Algo que, incorporado à compreensão comum, não encontra sustentação nas descobertas arqueológicas e, tampouco, nas pesquisas antropológicas. Recordemos que, conforme aponta Bourguignon, o sedentarismo, resultado da guinada cultural provocada pelo "sistema técnicoeconômico fundado na estocagem alimentar", para além dos impactos ambientais, veio acompanhado pela produção de excedentes e deu lugar, entre outros, a mazelas sociais até então inexistentes: a violência e a subjugação da mulher ao homem. (op. cit. Os. 200 - 204 e 217 - 224).
} 
inventos, ou a possibilidade de futuros acréscimos em seu conhecimento da natureza, inevitáveis em uma certa etapa do pensamento humano. (BURY, 1971, p. 18).

O ponto em que o filósofo e o antropólogo se encontram é no reconhecimento de que as coisas não ocorreram exatamente dessa forma. Se Benjamin fala em "ruínas", Ribeiro menciona "regressões". De fato, "os procedimentos diretos ou indiretos, intencionais ou não, de indução ao progresso" podem sofrer regressões socioculturais como, por exemplo, a super utilização de uma tecnologia eficiente, mas destruidora em sua utilização. ${ }^{14}$ (RIBEIRO, 2000, ps. 28 - 31). É certo que nem Benjamim, nem Ribeiro lidaram com os danos ecológicos como exemplos de "ruínas" ou de "regressões". No caso de Ribeiro, os exemplos citados poderiam ter sido tipificados como regressões de natureza ecológica. Mas essa não parece ser no texto, uma categoria trabalhada. ${ }^{15} \mathrm{E}$, no entanto, os elementos para essa classificação estão dados no correr da obra. Assim, a queima de carvão para a produção de vapor, o uso da energia hidráulica e, depois, a utilização de combustíveis fósseis para a os motores à explosão e a dependência das atividades produtivas frente a essas matérias primas potencializaram conseqüências dramáticas durante e em todo o percurso posterior à Revolução Industrial. E, é evidente, à forma como os homens organizaram sua subjetividade e as cidades em que passaram a viver. ${ }^{16}$

\section{AS CIDADES COMO LÓCUS DE PROBLEMAS}

\footnotetext{
${ }^{14}$ No texto, o exemplo citado por Ribeiro mostra que a agricultura de regadio em regiões do In do, do Nilo, do Tigre, do Eufrates, do Huang Ho e do Yang-Tse levou à perda de terras agriculturáveis por efeito da erosão, da alcalinização, da salinização das terras ou, mesmo, da putrefação das águas.

${ }^{15}$ No rigor, ao que tudo indica a categoria "regressão sócio cultural" não tem alcance para englobar os fenômenos que se manifestam concomitantemente e, mais, como decorrência de manifestações de "aceleração evolutiva". Ela seria utilizada para aquelas ocorrências que são impeditivas, como bloqueadoras, do processo civilizatório. Ainda assim, com algum investimento conceitual, algo a que nos propomos aqui, julgamos poder utilizá-la para os efeitos intrínsecos às tecnologias que produzem acelerações sócio culturais.

${ }^{16}$ Sobre a relação entre subjetividade e vida urbana, ver o clássico A metrópole e a vida mental, de SIMMEL. (1964).
} 
As primeiras cidades surgiram como resultado de transformações sociais gerais - econômicas, tecnológicas, políticas e culturais. Segundo Souza, elas aparecem

[...] quando, para além de povoados de agricultores (ou aldeias), que eram pouco mais que acampamentos permanentes de produtores diretos que se tornaram sedentários, surgem assentamentos permanentes maiores e muito mais complexos que vão abrigar uma ampla população de não-produtores: governantes (monarcas e aristocratas), funcionários (como escribas) sacerdotes e guerreiros. [...] Entretanto, as cidades continuaram a transformar-se durante os milênios seguintes ao seu aparecimento, e continuaram a transformar-se sem cessar. [...] daí surgem em momentos diferentes, novos termos e novos conceitos, como conurbação, metrópole e megalópole, que se acrescentam e enriquecem a nossa visão do que seja ou do que pode ser o fenômeno urbano. (SOUZA, 2011, 46)

Definitivamente, a partir da Revolução Industrial, as cidades conheceram, em escala mundial, um crescimento que absorvia população e efeitos do desenvolvimento econômico. Oportunidades e problemas tornaram-se faces de um mesmo processo. No campo das oportunidades, progressivamente e de forma não linear, ela foi transformada em espaço de realização das forças econômicas. Nas cidades enraizaram-se a oferta dos insumos necessários à alimentação da produção, o mercado de troca e consumo de bens, a administração pública, o lazer, a oferta de serviços que mantém a força de trabalho em condições de uso, tanto quanto a difusão de conhecimento, cultura e valores.

No campo dos problemas, enfatizando a dimensão ambiental, em certos casos o crescimento potencializou situações pré-existentes, em outros, deu origem àquilo que poderia ser chamado de poluição pós implantação das tecnologias de combustão a vapor. No primeiro, seria bobagem dizer que os aglomerados humanos da antiguidade, do medievo e do renascimento não poluiam. Consideremos os rios e veremos que eram depósitos de tudo o que se produzia como não utilizável, de resíduos das atividades humanas a fezes. ${ }^{17}$ Ocorre que, a partir do Século XIX, como já foi insinuado, as tranformações provocadas pelas novas tecnologias

\footnotetext{
${ }^{17}$ Durante muito tempo e, ainda hoje, em muitas cidades de São Paulo, por exemplo, permanecem sendo utilizados, inclusive institucionalmente, para absorção de resíduos.
} 
impuseram intensidades e velocidades únicas à poluição no planeta e em cada cidade, individualmente.

De fato, o equilíbrio dos ecossistemas foi impactado de tal forma que hoje, é difícil deixar de introduzir no vocabulário cotidiano expressões como aquecimento global e mudanças climáticas. Mas há também outros problemas nada desprezíveis introduzidos no dia a dia das cidades. Os efeitos dos poluentes emitidos para o ar, provenientes de atividades industriais e da utilização de veículos motorizados, deterioram as condições do planeta, tanto quanto a saúde e a qualidade de vida geral das pessoas. Os detritos, a sujeira, os resíduos em geral tomam milhares de metros quadrados nos municípios que são obrigados a dispor de áreas especiais para sua destinação. Seus riscos, por mais cuidadosos que sejam os empreendimentos, são conhecidos: doenças, mal cheiro, vetores de zoonoses, além, é óbvio, de contribuirem para o aquecimento global.

Mas a mais, as cidades têm sido construidas de maneira ecologicamente perversa. Para permanecermos em um único exemplo, a pavimentação em concreto ou asfalto contribui sobremaneira para a impermebilização do solo. Esse é um modelo que acentua, evidentemente, o calor. Além disso, as deficiências e, mesmo, em muitos casos, a inexistência de drenagem, tornam o meio urbano objeto frequente de enchentes. Via de regra, as correntes d'água provocadas em situações de enchente provocam também um "efeito lavagem". É meio para o lixo e poluentes em geral se espalharem por áreas do meio urbano, provocando outras consequências, entre elas a de sua evacuação através dos dutos que levam a mananciais e, mesmo, reforço para o entupimento de bueiros.

\section{PENSAR A CIDADE, PLANEJAR A CIDADE}

Considerada como espaço de oportunidades e problemas, não por acaso o fim do século XIX presenciou o início dos estudos da cidade. A palavra urbanismo foi criada tão somente para servir de nome a esta nova realidade. Ela designa, conforme afirma Harouel, (1990), uma grande parte do que diz respeito à cidade: 
obras públicas, morfologia urbana, planos urbanos, práticas sociais e pensamento urbano, legislação e direito relativo à cidade. Segundo Choay, (1965), o termo lida com os meios de abordagem da organização espacial dos estabelecimentos humanos. Ele se diferencia das artes urbanas anteriores. Segundo a autora, o urbanismo está relacionado com a expansão da sociedade industrial e se refere a uma disciplina com caráter reflexivo e crítico e intencionalidade científica. Expressão de um momento histórico que sugere modelos ideais para as cidades, o urbanismo adota o plano e o zoneamento como mecanismos principais de ordenamento, regulação, uso e ocupação do solo. Supõe apenas planejador e político. O primeiro voltado para o desenho, disciplinamento e organização do espaço. O segundo, aquele que decide programa e, por vezes, implanta o que foi sugerido pelo técnico.

As limitações inerentes a esse modelo não tardaram a serem apontadas. A literatura sobre o tema passou a denunciar que, ao permanecer no âmbito exclusivo do técnico e da esfera da decisão política, o processo de planejamento urbano tornou-se arbitrário, por vezes massificador e autoritário. Ele deixa de levar em consideração, como afirma ainda Choay, que a concepção e organização do espaço impõem a escolha de valores, dependentes de contextos culturais e de condições políticas e econômicas complexas. (1965). Isso faz com que o planejamento urbano seja antes de tudo um problema social e, portanto, uma questão a ser discutida com a sociedade. A contraposição passa a ser, então, aquela entre um processo cuja formatação se aliena em relação a um debate em torno a valores, direitos e, mesmo, interesses, e aquele que propõe um planejamento pautado pela participação democrática, assumindo, inclusive, o enfrentamento de conflitos de propostas e projetos.

\section{PLANEJAMENTO DA CIDADE E PARTICIPAÇÃO POPULAR}

A incorporação do processo de participação popular ao planejamento urbano no Brasil ocorreu em um momento de desenvolvimento, modificações em seu perfil social, sofisticação nas estruturas do Estado e, certamente, crescimento de suas 
cidades. Nesse quadro, manifesta-se também, uma intensificação, por parte da população, da percepção sobre a importância da sua participação e, sobretudo, do direito a uma sociedade democrática. E isso não ocorreu por acaso.

Não podemos esquecer que entre o final da década de sessenta e a metade dos anos oitenta, o Brasil vinha sendo governado por decisões de uma elite econômica e política que restringiu ao extremo a participação popular. E isso produz efeitos não apenas nas esferas de governança, mas também no âmbito da formação dos indivíduos. Tanto assim que, na opinião de Pateman, parece ser efetiva a diminuição da tendência para atitudes não democráticas por parte do indivíduo. E isso se transforma em efeito psicológico positivo a favor da democracia e da solidariedade e ainda, na percepção de que é somente possível a estabilidade política com o sistema representativo. (PATEMAN, 1992, 67). Esta aceitação da participação como uma movimentação da comunidade, como um engajamento, permite compreender avanços por parte da sociedade. Os indivíduos deixam de ser meramente caracterizados como espectadores e tornam-se articuladores da política.

A participação popular, ou cidadã implica, portanto, dinâmica política com novas formas e conteúdos. Conforme Nogueira, citando Teixeira, ela é "elemento da cidadania"... "no sentido cívico, enfatizando as dimensões da universalidade, generalidade, igualdade de direitos, responsabilidades e deveres". (NOGUEIRA, 2005, p. 142). Sua ampliação na gestão pública se deu tanto pela demanda social como por uma resposta do governo à sociedade. (Idem). Não se trata apenas de uma mudança política e teórico-ideológica, mas também uma resposta às exigências da modernidade e do mundo globalizado. (Ibidem). ${ }^{18}$

No caso brasileiro, talvez se possa estabelecer com a Constituição de 1988 uma linha de demarcação entre um antes e um depois que separa institucionalmente a lógica da participação do imperativo do silêncio. No que diz respeito especificamente às questões urbanas e ambientais, ela representa efetivamente

\footnotetext{
${ }^{18}$ Um exemplo, desse movimento, para Bucci, é a ênfase da participação popular dada pela Agenda Habitat em seu §179: "os governos devem garantir o direito de todos os membros da sociedade de participar ativamente dos assuntos da comunidade em que vivem e garantir a participação na adoção de políticas em todos os níveis". (BUCCl, 2010, p. 339).
} 
uma plataforma voltada para o direito à participação, ao fortalecimento de diferentes grupos e ao sentimento de pertencimento à esfera da cidadania. ${ }^{19}$

Assim, além de consagrada constitucionalmente, a participação popular foi fortalecida e definida pelo Estatuto da Cidade (Lei Federal, 10.257/2001), em seu artigo $2^{\circ}$, inciso II, como meio para atingir a gestão democrática na formulação, execução e acompanhamento de planos, programas e projetos de desenvolvimento urbano. $^{20}$ No mesmo 2 o artigo do Estatuto, a gestão democrática é considerada diretriz para que a política urbana atinja seu objetivo de "ordenar o pleno desenvolvimento das funções sociais da cidade e da propriedade urbana".

O conceito de gestão, por sua vez, deve ser entendido em seu sentido amplo, ou seja, como grande amplitude de responsabilidades de coordenação e planejamento. (BUCCI, 2010). Também não pode ser praticada pelo poder público somente como instrumento a serviço de concepções tecnocráticas, mas sim como real instrumento de promoção do direito à cidade, sem exclusões, para todos (Idem, 2010). Nesse quadro, a participação popular deve ser estimulada e promovida pelo poder público no planejamento urbano, a partir de quatro instrumentos possíveis, definidos por lei, para garantir a gestão democrática da cidade:

\footnotetext{
Art. 43 Para garantir a gestão democrática da cidade, deverão ser utilizados, entre outros, os seguintes instrumentos:

I - Órgãos colegiados de política urbana, nos níveis nacional, estadual e municipal;

II - Debates, audiências e consultas públicas;

III - Conferências sobre os assuntos de interesse urbano, nos níveis nacional, estadual e municipal;

"IV - Iniciativa popular de projeto de lei e de planos, programas e projetos de desenvolvimento urbano. (Estatuto da cidade, Lei $\mathrm{n}^{\circ}$ 10.257/2001).
}

\footnotetext{
19 Este exercício de retomada do processo de democracia experimentado com a Constituição Federal, no qual, entre outras coisas, a população passou a ter acesso a informação e pode participar dos rumos do planejamento do país foi, pouco tempo depois, fortalecido politicamente com a realização da Conferência das Nações Unidas para o Meio Ambiente e o Desenvolvimento, em 1992.

${ }^{20}$ Este documento vem seguido por outras importantes leis como a Política Nacional de Saneamento (Lei 11.445/07) e a Política Nacional de Resíduos Sólidos (12.305/10) que também passam a enfatizar a necessidade e a importância da participação popular na gestão ambiental urbana e principalmente no ordenamento democrático das cidades.
} 
Estamos lidando com a idéia de um novo pacto territorial que garanta a cidade para todos os seus habitantes. (BUCCI, 2010). Nesse pacto está implícito que os habitantes participem da formulação, execução e acompanhamento de planos, programas e projetos de desenvolvimento urbano. ${ }^{21}$ Isso significa que o complexo aparato regulatório que normatiza a produção e ocupação do espaço urbano municipal, bem como as diretrizes de políticas públicas deve ser, por exigência legal, submetidas à participação popular. ${ }^{22}$

Os canais possíveis de serem usados pela população são muitos, diversificados e estão disponíveis. Participar de associações é um deles. É meio para lutar pela sobrevivência de uma árvore, denunciar o uso irregular do solo e as condições de qualidade ambiental. É instrumento para impedir a deposição do lixo em terrenos, nas margens de rios, ou, até mesmo denunciar o barulho que perturba o sossego. (MALTA, 2004, p. 24). É instituição própria, inclusive para discussões em torno de direitos e interesses no planejamento urbano ambiental.

Para o poder público, a gestão democrática e sua prática produzem efeitos. A relação governante - governados muda. O poder público traz o "cidadão para a órbita do governo e o envolve nos assuntos governamentais". (NOGUEIRA, op. cit., p. 145). Outros efeitos são novas formas de controle social e a fusão da participação com decisão, execução, avaliação e controle, fazendo com que suas operações básicas fiquem articuladas (Idem.).

\footnotetext{
${ }^{21}$ Sem dúvida, com o Estatuto das Cidades, a grande novidade é o conceito que passa a informar o Plano Diretor. Ele se torna uma ferramenta de transformação da sociedade. Como reconhece o Senado Federal, ele é a peça básica da política de desenvolvimento e expansão urbana, do planejamento e gestão municipal. O plano diretor diz como o Estatuto será aplicado em cada município. Ele organiza o crescimento e o funcionamento da cidade e planeja o seu futuro. Determina qual o melhor uso da propriedade de acordo com a área em que está respeitando as especificidades e particularidades de sua população. Define o uso específico do espaço urbano. (BRASIL, 2001). Mais ainda: como está definido pelo Estatuto das Cidades, deve ser participativo. O princípio ativo de sua elaboração e implantação é, portanto, participação social. Sugere, efetivamente, que "democratizar as decisões é fundamental para transformar o planejamento da ação municipal em trabalho compartilhado entre os cidadãos e assumido pelos cidadãos, bem como para assegurar que todos se comprometam e sintam-se responsáveis e responsabilizados, no processo de construir e implantar o Plano Diretor. (ROLNIK, 2005, p.14).

22 Para Malta, 2004, por exemplo, a periferia rarefeita e as áreas centrais congestionadas podem ter seus processos sociais causadores revertidos, a partir da elaboração do planejamento urbano com preocupação social.
} 
Enfatizando o argumento: conforme Malta, o fato é que, "cada passo dado, por menor que possa parecer, poderá contribuir de modo positivo para alterar o processo mais amplo". (Op. cit., p.125). O desafio está no Poder Público Municipal entender o que significa a gestão democrática da cidade no seu sentido verdadeiro. Considerar a participação popular como uma prática que gera resultados para além do formal e do burocrático e que são necessárias iniciativa e criatividade da classe política local e dos tecnocratas públicos para conduzir esse processo de transformação social e utilizar, da melhor maneira possível, os seus resultados em prol da garantia da função social da cidade. Isso, em um momento em que a complexidade do mundo aponta para uma reestruturação radical dos discursos e das práticas.

De fato, a partir dos anos sessenta, frente às mazelas decorrentes de um desenvolvimento pautado pela barbárie ecológica, nos deparamos como um novo apelo, o do conceito da sustentabilidade. ${ }^{23} \cdot$, da preocupação com a capacidade do meio ambiente natural de suportar o desenvolvimento e processar toda a exaustão a que os recursos naturais são submetidos e como a população que ocupa este lugar se envolve com todo este processo e dialoga com estas transformações.

\section{A INTERVENÇÃO NA CIDADE: OS INSTRUMENTOS DISPONÍVEIS}

Os avanços nas formas de participação popular são evidentes. Mas, antes de discorrer sobre experiências municipais específicas, há duas características da cidade que precisam ser ressaltadas já que contextualizam os limites e as possibilidades de sucesso de iniciativas relacionadas à área meio ambiental. A primeira diz respeito ao fato de Araraquara possuir uma história de organização de entidades representativas da sociedade civil. Como já enfatizaram diversos autores, elas fazem parte da trajetória política do município e estiveram e estão ligadas a

\footnotetext{
${ }^{23}$ Por sustentabilidade entendemos aqui é o processo que busca harmonia entre a ação antrópica e o meio ambiente. Enquanto processo, envolve agentes que, de forma socialmente justa e economicamente viável, objetivam garantir às presentes e futuras gerações recursos, meio ambientais ou não, respeitando a biodiversidade e os atributos ecológicos existentes. (SANTOS FILHO \& WLUDARSKY, 2012, p. ).
} 
atividades filantrópicas, de moradores, religiosas e classistas. ${ }^{24} \mathrm{Na}$ contramão dessa presença, é notável que as administrações públicas não tenham tido preocupações maiores com pressões da sociedade civil organizada. Além de lidarem quase que exclusivamente com demandas pontuais, essas formas associativas "geralmente estiveram tuteladas por figuras políticas que negociavam suas solicitações em troca de votos". A segunda impõe reconhecer que o meio ambiente não consta da agenda de preocupações da população, pelo menos do ano 2000 em diante. ${ }^{25} \mathrm{Na}$ verdade, ao lado da área da cultura, o item não está presente em nenhuma das pesquisas de opinião organizadas ano a ano e que prevêem essa consulta. De fato, os focos de descontentamentos apontados pertencem às áreas da educação, lazer, zeladoria urbana, saúde, segurança pública e transporte. Com destaque permanente para 0 tripé zeladoria urbana, segurança e saúde, que disputam de forma costumeira o primeiro lugar.

Frente a esse diagnóstico, ocorre perguntar que instrumentos estão à disposição do poder público para proporcionar conhecimentos efetivos sobre os problemas da cidade, consciências das questões ambientais, acessos aos mecanismos da gestão pública e uma prática educacional que, focada na sustentabilidade, modificasse a pessoa e a realidade circundante. Vejamos duas linhas de trabalho possíveis.

\section{a) O ORÇAMENTO PARTICIPATIVO}

Convém lembrar que o município adotou, por força de lei, a criação de todos os conselhos necessários ao envolvimento dos segmentos organizados da sociedade civil nas áreas relacionadas a políticas públicas. Da saúde à assistência social, da segurança pública ao meio ambiente, cada um desses complexos de atividades voltadas para serviços a serem prestados à população é, pelo menos formalmente, acompanhado por um conselho municipal. Isso significa que algumas

${ }^{24}$ SANTOS FILHO, 2012.

${ }^{25}$ Sobre o assunto, a fonte é SANTOS FILHO, 2012. 
formas de participação popular foram estabelecidas por leis federais que regulam o próprio planejamento da cidade e de suas realizações. Há ainda aquelas, institucionalizadas ao longo do tempo, que foram invenções de governos, decorrência de posturas políticas e ideológicas. Entre elas, não há como deixar de mencionar uma experiência inovadora dos anos de 1990 e que se fez realidade, em Araraquara, a partir da década de $2000 .{ }^{26}$ Nos referimos ao Orçamento Participativo.

O Orçamento Participativo foi implantado na cidade com três objetivos principais: 1 - tornar-se um "instrumento responsável pela educação cidadã"; 2 "socializar a política orçamentária"; 3 - "promover uma administração das finanças municipais baseada na co-gestão." 27 De fato, em 2001, para a administração que recém iniciava sua gestão, tratava-se de "ampliar a base democrática firmada na participação popular no município" (CARVALHO \& ARAÚJO, 2010, p. 466). No rigor, a administração que assumiu em 2009 e teve sua continuidade confirmada nas urnas em 2012 manteve o mesmo discurso legitimador da proposta. Mas, o que chama atenção é a inexistência de ruptura com a natureza das demandas atendidas. Assim, no fundamental, não houve uma ruptura com aquilo que as pesquisas sugeriam como agenda de reivindicações da população. As cinco áreas apreciadas para investimentos do programa permanecem sendo a educação, a saúde, o desenvolvimento urbano, o transporte e, ocasionalmente, a cultura.

É verdade que o Orçamento Participativo trouxe para a órbita da participação nos negócios do município algumas milhares de pessoas. Ainda assim, a linha de envolvimento foi de queda. As hipóteses levantadas para a queda na presença de cidadãos nas plenárias são agrupadas em três grandes motivos: a ausência de uma sociedade civil disposta a participar do processo, o atraso da prefeitura em executar as propostas aprovadas e a falta de controle efetivo por parte

\footnotetext{
${ }^{26}$ O Orçamento Participativo teve sua experiência matriz em Porto Alegre, capital do estado do Rio Grande do Sul. Foi implantando em 1989 e inaugurou um modelo para os demais municípios brasileiros. Tornou-se exemplo de uma vivência profunda de gestão democrática por proporcionar a cada região do município gaúcho, reflexão, discussão, deliberação e o encaminhamento de propostas acerca do futuro da cidade. Para autores como Menegat e Almeida (2004), promoveu o sentimento de dignidade dos cidadãos, produziu uma profunda revolução na cultura política desta população e resgatou o sentimento de pertencimento a uma cidade que antes lhes voltava as costas.

${ }^{27}$ Sobre o perfil do Orçamento Participativo em Araraquara, ver CARVALHO \& ARAÚJJO, 2010.
} 
da população na execução da programação orçamentária. Sobre esse último tópico, nas palavras de um pesquisador:

$\mathrm{Na}$ medida em que a análise saiu da etapa de definição e se encaminhou para a etapa da execução dos investimentos, observa-se que o governo sempre retomou o controle do processo, reduzindo sobremaneira o poder dos representantes da população. (DA SILVA, 2011. P. 13).

Acrescente-se a esses problemas uma discussão nunca enfrentada e, portanto, nunca resolvida, sobre o significado real de participação da população nos destinos do orçamento, o montante do orçamento objeto dessa participação e, mesmo, a abrangência da discussão sobre os repasses federais e estaduais e teremos um quadro de descrédito quanto ao papel efetivo da sociedade no âmbito do Orçamento Participativo em Araraquara. ${ }^{28}$

Há uma pergunta feita por Pires \& Martins que certamente seria respondida pela negativa, considerada a experiência de Araraquara ${ }^{29}$. Assim, se procurarmos saber se o Orçamento Participativo "alterou de alguma maneira a qualidade da gestão orçamentária municipal”, a resposta é, seguramente, não. Algo no mesmo sentido poderia ser dito no que diz respeito a um envolvimento efetivo da população em relação à vida do município. Em primeiro lugar, é pequena a parcela da população que intervém efetivamente no processo. Em segundo lugar, envolvida, se vê às voltas com os tempos de realização das decisões. Em terceiro lugar, não possui qualquer poder quanto ao orçamento como um todo. Em quinto lugar, é alienada do processo de controle como um todo. Finalmente, definitivamente, na maneira como vem sendo organizado, o meio ambiente dificilmente será contemplado como prioridade. É manifesto o estado de carência da população frente a serviços tão fundamentais como saúde e educação, por exemplo. E, frente a essas necessidades, o meio ambiente é bagatelizado. Em muitos sentidos, considerada

\footnotetext{
${ }^{28}$ Uma análise importante sobre o desempenho do Orçamento Participativo em seus primeiros anos pode ser encontrada em Menegat e Almeida (2004).

${ }^{29}$ PIRES \& MARTINS, 2011, p. 108.
} 
essa dinâmica, o Orçamento Participativo não contribuiu para as aspirações de uma vida urbana sustentável.

\section{b) A EDUCAÇÃO AMBIENTAL COMO PRÁTICA DE PARTICIPAÇÃO}

Desde o fim dos anos 90 a educação ambiental é disposição decorrente dos Arts. 205 e 225 da Constituição Federal e prevista como política pública a ser realizada pela federação, estados, municípios, assim como pelo corpo da sociedade civil. Conforme a Lei № 9.795, de 1.999, ela é entendida como processo que visa o indivíduo e a coletividade. São sujeitos e objetos de um mesmo processo. Enquanto objetos vivem em um estado de determinação de seu modo de vida pautado por um meio sobre o qual restam dúvidas quanto ao seu potencial futuro e ao que produz como poluição no presente. Enquanto sujeitos, são responsáveis pelas transformações necessárias do status quo. O suposto é que um e outro construam valores sociais, conhecimentos, habilidades, atitudes e competências voltadas para a conservação de um bem - o meio ambiente - que é de uso comum do povo e tem como característica fundamental ser essencial à sadia qualidade de vida e sua sustentabilidade.

Nos termos da lei, é de responsabilidade do poder público instituir políticas públicas que promovam o "engajamento da sociedade na conservação, recuperação e melhoria do meio ambiente. Às empresas, entidades de classe, instituições públicas e privadas, por sua vez, caberiam a promoção de programas destinados à capacitação dos trabalhadores. Os objetivos dessas iniciativas estariam destinados "à melhoria e ao controle efetivo sobre o ambiente de trabalho, bem como sobre as repercussões do processo produtivo no meio ambiente". Finalmente, os meios de comunicação partilhariam a "responsabilidade de uma atuação ativa e permanente na disseminação de informações e práticas" voltadas ao meio ambiente. Em qualquer caso, indivíduos e coletividades seriam protagonistas de atuações voltadas para a "formação de valores, atitudes e habilidades que propiciem a atuação 
individual e coletiva voltada para a prevenção, a identificação e a solução de problemas ambientais".

Naquilo que nos diz respeito mais de perto, convém observar que a educação ambiental, na letra e no espírito da lei, supõe entre outras exigências, o reconhecimento e o respeito à pluralidade e à diversidade individual e cultural. Enfatiza ainda a necessidade de um enfoque participativo e conceitua o meio ambiente em sua interdependência com o meio natural, o sócio-econômico e o cultural. Estabelece a sustentabilidade como valor a ser cultivado e considerado na práxis ambiental.

Ainda no quadro de nossos interesses, a legislação não deixou de perceber a complexidade das transformações exigidas pelo processo de educação ambiental. Assim, se um dos objetivos essenciais desse processo é o "estímulo e o fortalecimento de uma consciência crítica sobre a problemática ambiental e social", os sujeitos dessa prática não podem deixar de reconhecer "as múltiplas e complexas relações aí existentes e que envolvem aspectos ecológicos, psicológicos, legais, políticos, sociais, econômicos, científicos, culturais e éticos".

Com esse referencial em mente, nos interessa expor aqui três experiências de trabalho de educação ambiental desenvolvidas durante o ano de 2012. Cada um deles foi pensado com uma preocupação enfática na questão do envolvimento da população. Ainda que o primeiro caso seja o de um exemplo negativo, cada um deles contém implícita ou explicitamente conteúdos que permitem o estabelecimento de paradigma capaz de ajudar na elaboração de práticas que superem não apenas a criação de ruínas, mas modelos de vida individual ou coletiva pautados pela sustentabilidade. São eles:

\section{1 - Experiência habitacional}

Em caso descrito pela imprensa como de situação caótica, os moradores de um residencial somente tomaram contato com seus novos domicílios praticamente no momento da entrega das chaves. Os antecedentes deste segundo estudo de caso remontam aos problemas sociais e ambientais surgidos no âmbito desse 
condomínio situado no Jardim Iguatemi, zona sul da cidade. ${ }^{30}$ Com população estimada entre 750 e mil pessoas, a maioria delas na faixa de renda entre zero e três salários mínimos, o residencial, pouco tempo após a ocupação, começou a apresentar situações graves e auto-reprodutíveis. Ou seja, quanto menor a atenção dada a eles, quanto menor a capacidade de extirpar-los, maior sua potencialidade em tornarem-se mais intensos e extensos.

No diagnóstico produzido pela equipe da Secretaria Municipal de Meio Ambientes, os problemas foram divididos em três grupos. O primeiro, de questões institucionais anteriores à ocupação, incluía 1 - A organização "arquitetônica" dá origem a problemas. São muitos blocos e poucas áreas comuns; 2 - a irracionalidade do layout do empreendimento, por exemplo, na organização do despejo do lixo produzido pelos moradores. E, a julgar pelos registros sobre a insatisfação da população, também existiria um déficit na questão da acessibilidade; 3 - o sistema de organização condominial não levou em consideração o número e a distribuição de prédios; 4 - foi negligenciado: o estudo do perfil da população beneficiada e de suas necessidades e, 5 - em decorrência de três, ausência de uma retaguarda institucional que se antecipe aos problemas. Principalmente àqueles de natureza social.

O segundo grupo de problemas dizia respeito a questões que faziam parte da trajetória dos indivíduos que compõem a população: 1 - crianças e adolescentes fora da escola; 2 - baixa escolaridade; 3 - ausência de capacitação; 4 - desemprego; 5 doenças; 6 - deficiências. O terceiro grupo, por fim, considerou questões emergentes no contexto da vida coletiva: 1 - promiscuidade; 2 - vandalismo; 3 violência; 4 - drogas; 5 - tráfico e 6 - prostituição.

A imbricação desses três grupos de problemas provocava uma situação que obrigou uma série de iniciativas conjuntas por parte de várias secretarias da prefeitura e outras instituições. Mas no que interessa a esta reflexão, o que se pode ver é a completa ausência de um trabalho de participação da população no projeto

\footnotetext{
${ }^{30}$ Ver Santos Filho \& Oliveira, 2012.
} 
e, sobretudo, inexistência de um esforço de educação ambiental. É provável que, com a participação dos futuros moradores na elaboração do projeto, conceitos e sugestões quanto ao planejamento dos espaços e, mesmo de soluções para questões como a do lixo produzido no local tivessem suprido o vazio de propostas perceptíveis em um trabalho arquitetônico que não considerou adequadamente necessidade.

\section{2 - Infraestrutura de saneamento.}

A segunda experiência escolhida como estudo de caso para a reflexão em curso refere-se à implantação do Programa de Aceleração do Crescimento conhecido como PAC do Saneamento, um programa financiado pelo governo federal para levar água e esgoto a comunidades desprovidas desta infra-estrutura. No caso, as localidades do município de Araraquara desprovidas deste benefício eram chácaras de recreio- região do Parque Planalto e Chácara Flora bem como o Distrito Industrial Omar Maksoud e Parque das Laranjeiras- áreas na interface das zonas rural e urbana.

A concepção do projeto foi elaborada por técnicos que tiveram apenas um contato preliminar com a população. Porém, na fase inicial de implantação do projeto executivo, toda a concepção deste mesmo projeto foi exaustivamente discutida com a comunidade beneficiada. Inúmeras reuniões e visitas foram feitas a esta população. Foi notório perceber que a partir do momento em que a informação é apresentada de maneira a permitir o entendimento de todo o processo tem-se a população como parceira e protagonista.

Lembrando ainda a proposição de Menegat e Almeida (2004), foi apresentada a informação, ou seja, proporcionou-se um processo de conhecimento do ambiente, uma sinergia entre o saber técnico e a realidade local, o cotidiano da comunidade e a partir disso ocorre simultaneamente um envolvimento desta população com o fato em si. Como afirma Pronsato (2005), houve o envolvimento da comunidade, porque ocorreu um planejamento participativo, uma identificação que é referenciada pela noção de território, de lugar, de pertencer e ser responsável por este lugar. Neste sentido podemos dizer que esta experiência foi positiva, pois não foi especificamente 
apenas o olhar do técnico sobre uma necessidade, mas um olhar compartilhado sobre uma localidade que integra um todo, a cidade. Portanto, incluiu o respeito à paisagem natural, à história de cada morador e os laços criados em relação ao local, sem processos de arbitrariedade deste o espaço, priorizando a comunicação e o respeito com o público.

\section{3 - Preservação de Nascente}

Outra experiência positiva, também vivenciada no município de Araraquara, refere-se à recuperação de uma área de preservação permanente e o envolvimento da população local. Inicialmente o projeto de recuperação previa o plantio de espécies nativas na área compreendida pela nascente do Córrego água Branca, atualmente bastante urbanizada e tendo em seu entorno núcleos de habitação popular de baixa renda. O local era palco de inúmeros problemas ambientais e sociais. Desde ocupação de animais na área de preservação permanente, deposição irregular de lixo e entulho, queimadas, esconderijo para usuários de entorpecentes e por fim área utilizada para a realização de práticas religiosas.

Do ponto de vista ambiental a necessidade de intervenção na área deveria ser rápida e imediata para evitar o rápido processo de degradação e conseqüentemente assoreamento e poluição do corpo d'água. Para tanto se apresentou o projeto para a comunidade escolar e na seqüência para os demais seguintes do local: comerciantes, lideranças religiosas, agentes comunitários de saúde e agentes sociais.

Sendo de conhecimento da comunidade local, iniciou-se a execução do projeto com a limpeza da área e posteriormente plantio de espécies nativas. A cada fase do projeto a comunidade era ouvida e convidada a participar, opinar e fiscalizar. Obteve-se sucesso, a participação da comunidade garantiu a intervenção técnica, a confiança na gestão pública, a transformação estética e ambiental de uma área antes, extremamente depauperada e a melhoria da qualidade de vida do local. Hoje, ao que tudo indica, os cidadãos locais partilham conceitos comuns sobre o espaço urbano construído e sobre o meio ambiente natural. . 


\section{CONCLUSÕES}

Ao longo do texto em que apresentamos uma reflexão em torno da questão da participação popular em torno dos problemas ambientais, mostramos que a legislação brasileira é atualíssima em relação ao tema. Na verdade, já alcançou a maioridade e, reconhecidamente, o fez com maturidade, dando conta de uma complexidade de assuntos que põe o governante em condições de dar saltos de qualidade na gestão da sustentabilidade. Saltos, aliás, necessários e, é certo, urgentes. Afinal o processo civilizatório abriga em sua história ruínas, regressões que não estão ocultas, possuem nome e sobrenome. A humanidade não pode continuar a ser impelida "incessantemente em direção ao futuro, enquanto a montanha de ruínas cresce".

Se, para usar as palavras dos frankfurtianos, isso se deveu ao domínio da razão instrumental, desde os anos 60 a governança internacional vem alertando para a necessidade de um novo padrão de comportamento. Ao lado da bandeira pela sustentabilidade, todos os organismos internacionais clamam pela necessidade de a gestão sobre o meio ambiente deixar as fronteiras do gabinete dos técnicos e ir às ruas, às praças, às escolas, às universidades, ao chão das indústrias, enfim, caminhar na direção de uma participação efetiva da população nos negócios públicos.

E é natural que isso aconteça dessa forma. Afinal, as cidades foram transformadas ao longo do tempo em territórios de oportunidades e de problemas. Se o urbano é espaço de problemas, se esses problemas são sociais em sua caracterização, são, portanto, quase que por definição, questões a serem discutidas na qualidade de problemas públicos por cidadãos. $E$ isso é dito e reconhecido, como anunciamos, pela Constituição Federal, pelo Estatuto da Cidade, enfim, por toda uma legislação que segue as conquistas duramente realizadas pelos movimentos sociais desde os anos oitenta.

É visível a existência de avanços nas formas de participação popular. Mas não podemos esquecer as lições de Chico de Oliveira. Permitimo-nos lembrá-las e 
dizer que ainda permanece como tarefa histórica avançar na socialização da política, alargar os espaços de participação da grande massa popular nas decisões. E acrescentaríamos: incorporar experiências, aproveitar saberes, escutar esperanças e expectativas, entrar em contato com subjetividades, com necessidades.

Tarefa nada fácil reconhecemos. Deixamos claro no texto a importância da mudança da realidade através da mudança do próprio sujeito da transformação. Em outras palavras: supusemos que, na defesa do meio ambiente, sua preservação e desenvolvimento dependem de forma imprescindível de uma atitude pró-ativa por parte dos sujeitos. Sujeitos, fomos realistas quanto a isso, cujas trajetórias podem ter sido de desconhecimento, de indiferença ou, mesmo, agressão/cumplicidade em relação à questão ambiental.

Justo por reconhecermos isso, sugerimos a fundamentalidade da educação ambiental. E o reconhecimento se justifica porque seu suposto é que indivíduos e coletividades, cidadãos, estado ou empresas, todos e qualquer um construam valores sociais, conhecimentos, habilidades, atitudes e competências voltadas para a conservação de um bem - o meio ambiente - que é de uso comum do povo e tem como característica fundamental ser essencial à sadia qualidade de vida e sua sustentabilidade. De fato, na forma como é proposta, não resta senão ao educador, ao sujeito da práxis, atender às demandas da tese de Marx: transformar a realidade, transformando-se.

Se exemplos tirados de uma realidade do interior de São Paulo ajudam é porque mostram os limites e as possibilidades de avançar nesse paradigma. Assim, ainda que se tenha definido o Orçamento Participativo como experiência de educação cidadã, a verdade é que, enquanto programa do poder executivo na direção da sociedade, para que chegasse a esse objetivo seriam necessárias vontade e segurança políticas. Em sua falta, permaneceu sua face ritualística e, com ela, o status quo. Na mesma direção, a experiência com uma população carente de moradia. A atitude foi francamente paternalista, substituta de um protagonismo popular efetivo. 
Obrigados a por um ponto final a essas aproximações, não é difícil perceber a persistência de perguntas. "Como evitar que nossas cidades se estendam e se diluam, percam a forma e a alma?", perguntava Le Corbusier, muito tempo atrás. $(2010,12)$. Existe um modelo de gestão a ser seguido? Existe um ideal de cidade queremos? Há uma fórmula sobre como ocupar este espaço? Existe um saber sobre como lidar com interesses econômicos, ambiente construído, ambiente natural, consciência? Há uma fórmula para conjugar tudo isto? Provavelmente, não.

Estamos certos, no entanto, quanto à inexistência de fórmulas e procedimentos mágicos para o planejamento urbano. Ainda assim, os casos trazidos à baila são consistentes. Permitem inferir que o município ainda atua gerando as condições da ruína. São governos de oportunidades perdidas. E vão à contramão das necessidades de um mundo de hoje, de gerações do futuro. É uma percepção que abre a oportunidade para uma nova pergunta: a quem não interessa a participação popular?

\section{REFERÊNCIAS}

ALMEIDA, Gerson; MENEGAT, Rualdo. Sustentabilidade e Democracia: Elementos Para Uma Estratégia de Gestão Ambiental Urbana no Brasil - Texto preparado e redigido para a ANAMMA - Associação Nacional de Municípios e Meio Ambiente, 2003.

ALMEIDA, Gerson; MENEGAT, Rualdo. (org). Desenvolvimento sustentável e Gestão ambiental nas cidades: estratégias a partir de Porto Alegre: Editora da UFRGS, 2004.

BENJAMIN, Walter. On the Concept of History. www.sfu.ca/ andrewf/CONCEPT2.html. Acesso em 25/08/2013.

BRASIL. Perguntas e respostas sobre 0 plano Diretor. http://www.senado.gov.br/programas. Acesso em 30/11/2012.

BOURGUIGNON, André. História Natural do Homem. 1. O homem imprevisto. Jorge Zahar Editor. Rio de Janeiro, 1990.

BUCCI, Maria Paula Dallari. Gestão democrática da cidade. Estatuto da Cidade (comentários à Lei Federal 10.257/2001). Coordenadores: Adilson Abreu Dallari e Sérgio Ferraz. São Paulo, 2006. 
BURY, John. La idea del progreso. Alianza Editorial, Madrid, 1971.

CHAUÍ, Marilena. Conformismo e resistência. Brasiliense, São Paulo, 1986.

CHOAY, Françoise. Urbanismo. Utopias e realidades: uma antologia. São Paulo: Perspectiva, 1961.

HAROUEL, Jean-Louis. História do urbanismo. Tradução Ivone Salgado. Campinas, SP- Papirus, 1990.

LE CORBUSIER. Planejamento urbano. Tradução Lucio Gomes Machado. São Paulo: Perspectiva, 2010.

MALTA, Cândido. Práticas para uma nova cidade. Práticas de Cidadania. Organização: Jaime Prinsky. São Paulo, 2004.

MARX, KARL. Thèses sur Feuerbach. In L'Idéologie Allemande. Éditions Sociales, Paris, 1976. Ps. $1-3$.

NOGUEIRA, Marco Aurélio. Um Estado para sociedade civil: tema céticos e políticos da gestão democrática. São Paulo, 2005.

OLIVEIRA, S. C. de; CASSOLI, S. C. F. As melhorias das obras do PAC. 2008. Cartilha institucional, 2008,12p.

OLIVEIRA, Simone Cristina de; SANTOS FILHO, José dos Reis. Olhar a paisagem. Experiências em educação ambiental nas bacias hidrográficas da área urbana do

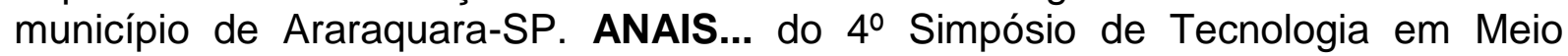
Ambiente e Recursos Hídricos. Org. José Carlos Toledo Venizizni Junior e Jozrael Henriques Rezende- São Carlos, Rima Editora, 2012, 468p. ISBN 978.85.7656.271.9

PATEMAN, Carole. Participation e democracy theory. Cambridge: Cambridge University, 1992.

PRONSATO, Silvia. Arquitetura e Paisagem. Projeto participativo e criação coletiva. Annablume, 2005.

RIBEIRO, Darcy. O processo civilizatório. Etapas da evolução sociocultural. Companhia das Letras/Publifolha, São Paulo, 2000.

RONILK, Raquel; PINHEIRO, Otilie. Plano Diretor participativo: Guia para elaboração pelos municípios e cidadãos. Brasília: Ministério das Cidades: CONFEA, 2005.

SANTOS FILHO, José dos Reis \& OLIVEIRA, Simone C. de. Residencial Oitis. Caracterização inicial e proposta de trabalho sócio-ambiental. Mimeo. Prefeitura do Município de Araraquara. Secretaria Municipal de Meio Ambiente. Araraquara, maio de 2012. 
SANTOS FILHO, José dos Reis. População de Araraquara define suas demandas. Relatório de Pesquisa. Mimeo. Araraquara, Datapress/Núcleo de Pesquisas sobre Situações de Violência e Políticas Alternativas. Unesp/FCL/CAr. Outubro de 2012.

SANTOS FILHO, José dos Reis; WLUDASRSKI, Stefânia. Meio ambiente: legitimidade, base institucional e políticas públicas, um estudo de caso. Anais do $4^{\circ}$ Simpósio de Tecnologia em Meio Ambiente e Recursos Hídricos. Org. José Carlos Toledo Venizizni Junior e Jozrael Henriques Rezende- São Carlos, Rima Editora, 2012, 468p. ISBN 978.85.7656.271.9.

SIMMEL, Georg. The Metropolis and Mental Life. In: WOLF, Kurt. H. (Org.). The Sociology of Georg Simmel, The Free Press, New York, 1964, ps. 409 - 426.

SOUZA, Marcelo Lopes. ABC do desenvolvimento urbano. Rio de Janeiro: Bertrand Brasil, 2011.

VILLAÇA, Flávio. A crise do planejamento. São Paulo em Perspectiva, v.09/ no․2/ Abr-Jun 1995, p 45-51.

\section{Legislação Citada}

Constituição da República Federativa do Brasil

Lei Federal № 9.795, de 1.999.

Lei Federal no 10.257, de 2.001. 